\title{
Decision-making of Big Data Business Investment in Supply Chain
}

\author{
Xie $Y u^{1, a}$ \\ ${ }^{1}$ School of Management, Tianjin University of Technology, Tianjin, 300384, China \\ a Email: 18202295922@163.com
}

Keywords: big data; supply chain coordination; decision-making; revenue sharing contract

\begin{abstract}
In order to explore the decision-making problem of supply chain enterprises investing in big data business, for a two-stage supply chain consisting of a single manufacturer and a single retailer, considering that supply chain companies reduce their internal costs by investing in big data services, at the same time increase the product sales ratio, discuss separately the impact of or the retailer or the manufacturer investing in big data services on the supply chain and its members' profits, the big data business cost constraints that can increase the revenue of supply chain companies was driveled, which will be analyzed and verified by numerical study.
\end{abstract}

\section{Introduction}

The development of information technologies such as mobile Internet, Internet of Things, cloud computing, and artificial intelligence has driven the rapid growth and recording of global data [1]. The data recorded by humans in the past two years has surpassed the number of all human history records in the past [2]. At the same time, cloud computing has revolutionized the IT industry, requiring enterprises to pay only for the resources and services they use, thereby reducing the cost of storing and analyzing data [3], which indicates the arrival of the era of big data [4].

In the era of big data, data has penetrated into various industries and business functions and has become an important production factor [5]. Although the use of big data can bring huge benefits to enterprises, enterprises need to spend huge costs to acquire and analyze big data, and most enterprises do not have the ability to handle big data. Therefore, many enterprises choose to outsource their big data services to professional big data service providers, who use big data technology to provide valuable big data information to enterprises while helping enterprises tap potential consumers.

The literature related to the research topic of this paper mainly refers to investment decision-making of big data business and supply chain coordination and. First of all, regarding the application of big data in the supply chain, the research is mainly qualitative research and empirical research, and quantitative research is less. Liu and Yi [6] discussed the impact of supply chain members investing alone or both in big data services on the benefits of the supply chain members and the supply chain in a decentralized decision-making supply chain. Secondly, regarding to supply chain coordination research, a large number of studies prove that supply chain coordination contract can solve the double marginalization effect of supply chain and realize supply chain coordination [7].

However, the above studies all assume that the retailer's order quantity is equal to the market demand, that is, the products ordered by the retailer can be sold out during the sales period. But in fact, because of the uncertainty in the market, retailers cannot accurately predict the market demand for the products. On the other hand, only enterprises in the supply chain only consider that they can reduce the internal cost of the enterprise by investing in big data services, without considering that enterprises can explore potential consumers by investing in big data services.

\section{Model Description and Parameter Setting}

This paper considers a two-stage supply chain model consisting of a manufacturer $M$ and a retailer $R$. Here, the manufacturer is the leader of the Stackelberg game, which only produces and 
sells a single brand of products to the downstream retailer, unit production costs of the product is $c_{M}$, and the manufacture determines the wholesale price of the product $w_{M}^{i}$. The retailer is the follower of the Stackelberg game, determining the order quantity of the product based on the manufacturer's wholesale price $w_{M}^{i}$ and its own forecast of product demand $Q^{i}$. Here, $i=$ $\{N B D 、 R B D\}$ represent the investment situation of two big data businesses respectively: supply chain members not investing in big data business, the retailer invests big data business only. Let

$\pi_{R}^{i}, \pi_{M}^{i}, \pi_{S C}^{i}$ represent the profit of the retailer, the manufacture and the supply chain under model $i$. It is known that the unit inventory cost of the manufacturer and the retailer is $v_{M}$ and $v_{R}$ respectively, in which we have $c_{M}+v_{M}<w_{M}$, and unit sales cost of the retail is $c_{R}$.

Due to the uncertainty in the market, the retailer can not accurately predict the demand of the products, and the retailer only has one opportunity to order the products, thus the retailer chooses to order more products in order to avoid product shortages affecting goodwill, therefore, the products ordered by the retailer cannot be sold in full, assuming that the ratio between the actual demand and the order quantity of the products is $\alpha^{i}, \alpha^{i} \in[0,1]$, that is, during the sales season, the actual number of products sold is $\alpha^{i} Q^{i}$. The surplus products $\left(1-\alpha^{i}\right) Q^{i}$ that have not been sold will be processed at the end of the season, and product salvage value is $s$ which satisfied $s<w_{M}^{i}$. This paper considers the market demand related to the product sales price, thus assumes the inverse demand function of the market is $P^{i}=a-b \alpha^{i} Q^{i}$ with $w_{M}^{i}+v_{R} \leq P^{i}$, where $a 、 b$ is constant.

Enterprises in the supply chain choose to outsource big data services to big data service providers, and big data service providers charge for big data technology service fees $\mathrm{c}_{\mathrm{B}}$, by analysis, enterprises in the supply chain can obtain two different benefits by investing in big data services: 1 ) reduce the internal cost of the enterprises, and the cost optimization coefficient is $\theta, \theta \in(0,1]$, we assume that under RBD mode, the cost optimization coefficients of supply chain enterprises investing in big data services are consistent. 2) tap potential market demand and predict product demand more accurately, thus increasing product sales ratio $\alpha^{\mathrm{i}}$, similarly, under RBD mode, the product sales ratio is the same and satisfies $\alpha^{\mathrm{NBD}}<\alpha^{\mathrm{RBD}}$.

This paper assumes that the manufacturer and the retailer is risk-neutral, that the manufacturer has enough capacity to meet the retailer's order quantity, and the information between the manufacturer and the retailer is completely symmetrical.

\section{Supply Chain Revenue Model and Investment Decision}

\subsection{NBD mode: The supply chain members not investing in big data services}

Under NBD model, the supply chain is a decentralized decision-making supply chain. The retailer and the manufacturer act as different decision-making bodies, and make decisions based on maximizing their own profits. The profit function of the retailers, the manufacturer, and the supply chain is as follows:

$$
\begin{aligned}
& \pi_{\mathrm{R}}^{\mathrm{NBD}}=\mathrm{P}^{\mathrm{NBD}} \cdot \alpha^{\mathrm{NBD}} \mathrm{Q}^{\mathrm{NBD}}-\left(\mathrm{c}_{\mathrm{R}}+\mathrm{v}_{\mathrm{R}}+\mathrm{w}_{\mathrm{M}}^{\mathrm{NBD}}\right) \mathrm{Q}^{\mathrm{NBD}}+\mathrm{s} \cdot\left(1-\alpha^{\mathrm{NBD}}\right) \mathrm{Q}^{\mathrm{NBD}} \\
& \pi_{\mathrm{M}}^{\mathrm{NBD}}=\mathrm{w}_{\mathrm{M}}^{\mathrm{NBD}} \mathrm{Q}^{\mathrm{NBD}}-\left(\mathrm{c}_{\mathrm{M}}+\mathrm{v}_{\mathrm{M}}\right) \mathrm{Q}^{\mathrm{NBD}} \\
& \pi_{\mathrm{SC}}^{\mathrm{NBD}}=\pi_{\mathrm{R}}^{\mathrm{NBD}}+\pi_{\mathrm{M}}^{\mathrm{NBD}}
\end{aligned}
$$

Here, the market inverse demand function under NBD mode is:

$$
\mathrm{P}^{\mathrm{NBD}}=\mathrm{a}-\mathrm{b} \alpha^{\mathrm{NBD}} \mathrm{Q}^{\mathrm{NBD}}
$$

By using the backward induction method, the manufacturer's optimal wholesale price, the retailer's optimal product order quantity and the optimal retail price can be obtained in turn:

$$
\begin{aligned}
\mathrm{w}_{\mathrm{M}}^{\mathrm{NBD} *} & =\left[\mathrm{a} \alpha^{\mathrm{NBD}}+\mathrm{s}\left(1-\alpha^{\mathrm{NBD}}\right)-\mathrm{c}_{\mathrm{R}}-\mathrm{v}_{\mathrm{R}}+\mathrm{c}_{\mathrm{M}}+\mathrm{v}_{\mathrm{M}}\right] / 2 \\
\mathrm{Q}^{\mathrm{NBD} *} & =\left[\mathrm{a} \alpha^{\mathrm{NBD}}+\mathrm{s}\left(1-\alpha^{\mathrm{NBD}}\right)-\mathrm{c}_{\mathrm{R}}-\mathrm{v}_{\mathrm{R}}-\mathrm{c}_{\mathrm{M}}-\mathrm{v}_{\mathrm{M}}\right] / 4 \mathrm{~b} \alpha^{\mathrm{NBD}^{2}}
\end{aligned}
$$




$$
\mathrm{P}^{\mathrm{NBD} *}=\left[3 \mathrm{a} \alpha^{\mathrm{NBD}}-\mathrm{s}\left(1-\alpha^{\mathrm{NBD}}\right)+\mathrm{c}_{\mathrm{R}}+\mathrm{v}_{\mathrm{R}}+\mathrm{c}_{\mathrm{M}}+\mathrm{v}_{\mathrm{M}}\right] / 4 \alpha^{\mathrm{NBD}}
$$

Based on equations (5), (6), and (7), we can have the optimal profit of the retailer, the manufacturer, and the overall supply chain under NBD mode:

$$
\begin{aligned}
& \pi_{\mathrm{R}}^{\mathrm{NBD} *}=\left[\mathrm{a} \alpha^{\mathrm{NBD}}+\mathrm{s}\left(1-\alpha^{\mathrm{NBD}}\right)-\mathrm{c}_{\mathrm{R}}-\mathrm{v}_{\mathrm{R}}-\mathrm{c}_{\mathrm{M}}-\mathrm{v}_{\mathrm{M}}\right]^{2} / 16 \mathrm{~b} \alpha^{\mathrm{NBD}^{2}} \\
& \pi_{\mathrm{M}}^{\mathrm{NBD} *}=\left[\mathrm{a} \alpha^{\mathrm{NBD}}+\mathrm{s}\left(1-\alpha^{\mathrm{NBD}}\right)-\mathrm{c}_{\mathrm{R}}-\mathrm{v}_{\mathrm{R}}-\mathrm{c}_{\mathrm{M}}-\mathrm{v}_{\mathrm{M}}\right]^{2} / 8 \mathrm{~b} \alpha^{\mathrm{NBD}^{2}} \\
& \pi_{\mathrm{SC}}^{\mathrm{NBD} *}=3\left[\mathrm{a} \alpha^{\mathrm{NBD}}+\mathrm{s}\left(1-\alpha^{\mathrm{NBD}}\right)-\mathrm{c}_{\mathrm{R}}-\mathrm{v}_{\mathrm{R}}-\mathrm{c}_{\mathrm{M}}-\mathrm{v}_{\mathrm{M}}\right]^{2} / 16 \mathrm{~b} \alpha^{\mathrm{NBD}^{2}}
\end{aligned}
$$

Theorem 1 Since supply chain members make decisions with the goal of maximizing their own profits, in order to ensure the normal operation of the supply chain, the retailer's order quantity and the profit of the supply chain members must be met $\mathrm{Q}^{\mathrm{NBD} *}>0, \pi_{\mathrm{R}}^{\mathrm{NBD} *}>0, \pi_{\mathrm{M}}^{\mathrm{NBD} *}>0$, we get:

$$
\alpha^{\mathrm{NBD}}>\left(\mathrm{c}_{\mathrm{R}}+\mathrm{v}_{\mathrm{R}}+\mathrm{c}_{\mathrm{M}}+\mathrm{v}_{\mathrm{M}}-\mathrm{s}\right) /(\mathrm{a}-\mathrm{s})
$$

\subsection{RBD mode: the retailers investing in big data services only}

\subsubsection{Supply Chain Revenue Model}

Under RBD model, the retailer and the manufacturer still make decisions based on the goal of their own profit maximization, but the retailer can reduce their internal operating costs, including sales costs and inventory costs, by investing in big data services, at the same time, retailers can better tap potential consumers and increase the product sales ratio, therefore, the profit functions of retailers, manufacturers, and the supply chain are:

$$
\begin{aligned}
& \pi_{\mathrm{R}}^{\mathrm{RBD}}=\mathrm{P}^{\mathrm{RBD}} \cdot \alpha^{\mathrm{RBD}} \mathrm{Q}^{\mathrm{RBD}}-\left(\theta \mathrm{c}_{\mathrm{R}}+\theta \mathrm{v}_{\mathrm{R}}+\mathrm{w}_{\mathrm{M}}^{\mathrm{RBD}}\right) \mathrm{Q}^{\mathrm{RBD}}+\mathrm{s} \cdot\left(1-\alpha^{\mathrm{RBD}}\right) \mathrm{Q}^{\mathrm{RBD}}-\mathrm{c}_{\mathrm{B}} \mathrm{Q}^{\mathrm{RBD}} \\
& \pi_{\mathrm{M}}^{\mathrm{RBD}}=\mathrm{w}_{\mathrm{M}}^{\mathrm{RBD}} \mathrm{Q}^{\mathrm{RBD}}-\left(\mathrm{c}_{\mathrm{M}}+\mathrm{v}_{\mathrm{M}}\right) \mathrm{Q}^{\mathrm{RBD}} \\
& \pi_{\mathrm{SC}}^{\mathrm{RBD}}=\pi_{\mathrm{R}}^{\mathrm{RBD}}+\pi_{\mathrm{M}}^{\mathrm{RBD}}
\end{aligned}
$$

Here, the market inverse demand function under RBD mode is

$$
\mathrm{P}^{\mathrm{RBD}}=\mathrm{a}-\mathrm{b} \alpha^{\mathrm{RBD}} \mathrm{Q}^{\mathrm{RBD}}
$$

By using the backward induction method, we have:

$$
\begin{aligned}
\mathrm{w}_{\mathrm{M}}^{\mathrm{RBD} *}=\left[\mathrm{a} \alpha^{\mathrm{RBD}}+\mathrm{s}\left(1-\alpha^{\mathrm{RBD}}\right)-\theta \mathrm{c}_{\mathrm{R}}-\theta \mathrm{v}_{\mathrm{R}}+\mathrm{c}_{\mathrm{M}}+\mathrm{v}_{\mathrm{M}}-\mathrm{c}_{\mathrm{B}}\right] / 2 \\
\mathrm{Q}^{\mathrm{RBD} *}=\left[\mathrm{a} \alpha^{\mathrm{RBD}}+\mathrm{s}\left(1-\alpha^{\mathrm{RBD}}\right)-\theta \mathrm{c}_{\mathrm{R}}-\theta \mathrm{v}_{\mathrm{R}}-\mathrm{c}_{\mathrm{M}}-\mathrm{v}_{\mathrm{M}}-\mathrm{c}_{\mathrm{B}}\right] / 4 \mathrm{~b} \alpha^{\mathrm{RBD}}{ }^{2} \\
\mathrm{P}^{\mathrm{RBD} *}=\left[3 \mathrm{a} \alpha^{\mathrm{RBD}}-\mathrm{s}\left(1-\alpha^{\mathrm{RBD}}\right)+\theta \mathrm{c}_{\mathrm{R}}+\theta \mathrm{v}_{\mathrm{R}}+\mathrm{c}_{\mathrm{M}}+\mathrm{v}_{\mathrm{M}}+\mathrm{c}_{\mathrm{B}}\right] / 4 \alpha^{\mathrm{RBD}}
\end{aligned}
$$

Similarly, based on the equations (16), (17), and (18), under RBD mode, the maximum profits of retailers, manufacturers, and supply chains are respectively:

$$
\begin{aligned}
& \pi_{\mathrm{R}}^{\mathrm{RBD} *}=\left[\mathrm{a} \alpha^{\mathrm{RBD}}+\mathrm{s}\left(1-\alpha^{\mathrm{RBD}}\right)-\theta \mathrm{c}_{\mathrm{R}}-\theta \mathrm{v}_{\mathrm{R}}-\mathrm{c}_{\mathrm{M}}-\mathrm{v}_{\mathrm{M}}-\mathrm{c}_{\mathrm{B}}\right]^{2} / 16 \mathrm{~b} \alpha^{\mathrm{RBD}}{ }^{2} \\
& \pi_{\mathrm{M}}^{\mathrm{RBD} *}=\left[\mathrm{a} \alpha^{\mathrm{RBD}}+\mathrm{s}\left(1-\alpha^{\mathrm{RBD}}\right)-\theta \mathrm{c}_{\mathrm{R}}-\theta \mathrm{v}_{\mathrm{R}}-\mathrm{c}_{\mathrm{M}}-\mathrm{v}_{\mathrm{M}}-\mathrm{c}_{\mathrm{B}}\right]^{2} / 8 \mathrm{~b} \alpha^{\mathrm{RBD}^{2}} \\
& \pi_{\mathrm{SC}}^{\mathrm{RBD} *}=3\left[\mathrm{a} \alpha^{\mathrm{RBD}}+\mathrm{s}\left(1-\alpha^{\mathrm{RBD}}\right)-\theta \mathrm{c}_{\mathrm{R}}-\theta \mathrm{v}_{\mathrm{R}}-\mathrm{c}_{\mathrm{M}}-\mathrm{v}_{\mathrm{M}}-\mathrm{c}_{\mathrm{B}}\right]^{2} / 16 \mathrm{~b} \alpha^{\mathrm{RBD}^{2}}
\end{aligned}
$$

Theorem 2 Under RBD model, in order to keep the supply chain stable, the retailer's order quantity and the profit of the supply chain members must meet: $\mathrm{Q}^{\mathrm{RBD} *}>0, \pi_{\mathrm{R}}^{\mathrm{RBD} *}>0, \pi_{\mathrm{M}}^{\mathrm{RBD} *}>0$, thus we get

$$
\mathrm{c}_{\mathrm{B}}<a \alpha^{\mathrm{RBD}}+\mathrm{s}\left(1-\alpha^{\mathrm{RBD}}\right)-\theta \mathrm{c}_{\mathrm{R}}-\theta \mathrm{v}_{\mathrm{R}}-\mathrm{c}_{\mathrm{M}}-\mathrm{v}_{\mathrm{M}}
$$

Conclusion 1 When the cost that the retailer invests in the big data business is satisfied formula (22), enterprises in the supply chain have made the best decisions, and the benefits are positive, the supply chain also can run normally, thus the retailer will consider investing in big data services, otherwise, the retailer will give up investing in the business because the cost of big data services is 
too high.

\subsubsection{Decision making of retailer's investment in big data services}

Conclusion 2 In the case of satisfying $\alpha^{N B D}>\left(c_{R}+v_{R}+c_{M}+v_{M}-s\right) /(a-s)$ and $\mathrm{c}_{\mathrm{B}}<a \alpha^{\mathrm{RBD}}+\mathrm{s}\left(1-\alpha^{\mathrm{RBD}}\right)-\theta \mathrm{c}_{\mathrm{R}}-\theta \mathrm{v}_{\mathrm{R}}-\mathrm{c}_{\mathrm{M}}-\mathrm{v}_{\mathrm{M}}$, if the unit cost of the retailer's investment in the big data service is $c_{B}<\alpha^{R B D}\left(c_{M}+v_{M}+c_{R}+v_{R}-s\right) / \alpha^{N B D}-\left(c_{M}+v_{M}+\theta c_{R}+\theta v_{R}-s\right)$, then the retailer's profits will increase, at the same time, positive externalities increase the profits of the manufacturer and the supply chain. If the unit cost of big data service is $c_{B}>\alpha^{R B D}\left(c_{M}+v_{M}+\right.$ $\left.c_{R}+v_{R}-s\right) / \alpha^{N B D}-\left(c_{M}+v_{M}+\theta c_{R}+\theta v_{R}-s\right)$, the retailer' s profits will decrease, while the manufacturer's and the supply chain's profits will decrease, and retailers will not invest in big data services alone.

Proof First, we need to ensure that the supply chain can operate normally under both NBD and RBD modes, therefore, it is necessary to satisfy formula (11) and (22), then, compare the revenue models of the retailer, the manufacturer and the supply chain before and after the retailer invests in big data services only, let the difference of the retailer, the manufacturer and the supply chain's profit be $\Delta \pi_{R}^{R B D *}, \Delta \pi_{M}^{R B D *}, \Delta \pi_{S C}^{R B D *}$, when $\Delta \pi_{R}^{R B D *} \geq 0, \Delta \pi_{M}^{R B D *} \geq 0, \Delta \pi_{S C}^{R B D *} \geq 0$, we have,

$$
\mathrm{c}_{\mathrm{B}} \leq \alpha^{\mathrm{RBD}}\left(\mathrm{c}_{\mathrm{M}}+\mathrm{v}_{\mathrm{M}}+\mathrm{c}_{\mathrm{R}}+\mathrm{v}_{\mathrm{R}}-\mathrm{s}\right) / \alpha^{\mathrm{NBD}}-\left(\mathrm{c}_{\mathrm{M}}+\mathrm{v}_{\mathrm{M}}+\theta \mathrm{c}_{\mathrm{R}}+\theta \mathrm{v}_{\mathrm{R}}-\mathrm{s}\right)
$$

Corollary 1 Under RBD mode, from the formula (23), the maximum unit cost that the retailer is willing to undertake to invest in big data services is $\operatorname{maxc}_{B-R B D}=\alpha^{R B D}\left(c_{M}+v_{M}+c_{R}+v_{R}-s\right) /$ $\alpha^{\mathrm{NBD}}-\left(\mathrm{c}_{\mathrm{M}}+\mathrm{v}_{\mathrm{M}}+\theta \mathrm{c}_{\mathrm{R}}+\theta \mathrm{v}_{\mathrm{R}}-\mathrm{s}\right)$.

\section{Numerical Example}

To illustrate the validity of the above theorems and conclusions and to examine the impact of investment big data services on the supply chain and its members' benefits, numerical examples are used in this paper. Based on the study of Liu and Yi [16], let $c_{M}=9, v_{M}=1, c_{R}=1, v_{R}=1, s=$ $5, a=50, b=5, \theta=0.7$. According to theorem 1 , in order to ensure the normal operation of the supply chain under NBD mode, the sales ratio of the products must be satisfied with $\alpha^{\mathrm{NBD}}>$ $\left(c_{R}+v_{R}+c_{M}+v_{M}-s\right) /(a-s)=0.16$, without loss of generality, let $\alpha^{N B D}=0.7$, Under NBD model, the revenue of the supply chain and its members is $\left(\pi_{\mathrm{R}}^{\mathrm{NBD} *}, \pi_{\mathrm{M}}^{\mathrm{NBD} *}, \pi_{\mathrm{SC}}^{\mathrm{NBD} *}\right)=(15.31,30.62,45.93)$.

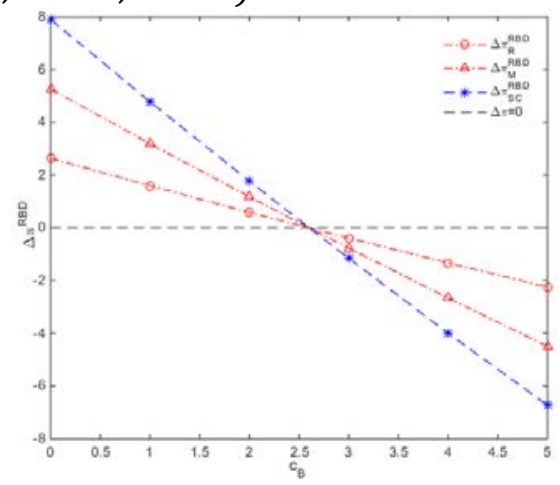

Fig. 1 The impact of the retailer's investment in big data on the supply chain and its members' profits under RBD mode

According to theorem 2, in order to ensure the stability of the supply chain under RBD model, the unit cost of the retailer's investment in big data services is met $c_{B}<a \alpha^{R B D}+s\left(1-\alpha^{R B D}\right)-$ $\theta c_{R}-\theta v_{R}-c_{M}-v_{M}=34.1$, also based on the formula (23), under RBD mode if and only if $c_{B} \leq \alpha^{R B D}\left(c_{M}+v_{M}+c_{R}+v_{R}-s\right) / \alpha^{N B D}-\left(c_{M}+v_{M}+\theta c_{R}+\theta v_{R}-s\right)=2.6$, let $c_{B}=1$, here we have the revenue of the supply chain and its members is $\left(\pi_{\mathrm{R}}^{\mathrm{RBD} *}, \pi_{\mathrm{M}}^{\mathrm{RBD} *}, \pi_{\mathrm{SC}}^{\mathrm{RBD} *}\right)=(16.91,33.82,50.73)$, these indicates that $\pi_{\mathrm{R}}^{\mathrm{RBD} *}>\pi_{\mathrm{R}}^{\mathrm{NBD} *}$, $\pi_{\mathrm{M}}^{\mathrm{RBD} *}>\pi_{\mathrm{M}}^{\mathrm{NBD} *}, \pi_{\mathrm{SC}}^{\mathrm{RBD} *}>\pi_{\mathrm{SC}}^{\mathrm{NBD} *}$, thus conclusion 1 and conclusion 2 are confirmed. Figure 1 shows 
the impact of the retailer's investment in big data only on the supply chain and its members' profits under RBD mode.

\section{Conclusion}

This paper builds a two-stage supply chain consisting of a single manufacturer and a single retailer, considering that enterprises in the supply chain can reduce their internal production costs by investing in big data services, and also tap potential customers and increase the product sales ratio. Then we analyze the two different decision-making modes of the supply chain's investment in big data services, the results show that when the retailer invests in big data business only, if the unit cost of investment in big data business meets the cost constraint, the retailer's own revenue will increase, while the supply chain and other members' revenue will increase.

\section{Acknowledgement}

The author is grateful for others' help and comments by the author's professor, teachers, friends, as well as the conference participants and editors.

\section{References}

[1] Waller M A, Fawcett S E. Data Science, Predictive Analytics, and Big Data: A Revolution That Will Transform Supply Chain Design and Management [J]. Journal of Business Logistics, 2013, 34(2).

[2] Gantz J, Reinsel D. The digital universe in 2020: Big data, bigger digital shadows, and biggest growth in the Far East [J]. IDC iView: IDC Analyze the future, 2012.

[3] Assunção M D, Calheiros R N, Bianchi S, et al. Big Data computing and clouds: Trends and future directions[J]. Journal of Parallel \& Distributed Computing, 2015.

[4] Brown B, Chui M, Manyika J. Are you ready for the era of 'big data'?[J]. Intermedia, 2011, 71(2).

[5] Manyika J, Chui M, Brown B, et al. Big Data: The Next Frontier for Innovation, Competition, and Productivity [J]. Analytics, 2011.

[6] Liu P, Yi S P. A study on supply chain investment decision-making and coordination in the Big Data environment [J]. Annals of Operations Research, 2017(6).

[7] Cachon G P. Supply Chain Coordination with Contracts [J]. Handbooks in Operations Research \& Management Science, 2003, 11(11). 